\title{
AO Trauma: Manual of fracture management
}

\section{Wrist-Book and E-Book, Jesse B. Jupiter, Douglas A. Campbell, Fiesky Nunez, Thieme Verlag New York, Stuttgart, Delhi, Rio de Janeiro, 2019, 524 pp., 2000 figs.; Hardcover, EUR (D) 174,99 EUR (A) 179,99 CHF 201,60, ISBN: 978-313-242841-6}

\author{
Alain G. Graftiaux ${ }^{1}$ - Pierre H. Kehr ${ }^{1}$ \\ Received: 10 August 2019 / Accepted: 14 September 2019 / Published online: 30 September 2019 \\ c) Springer-Verlag France SAS, part of Springer Nature 2019
}

Wrist surgery, especially the lower end of the radius, has evolved significantly in recent years. This prompted the AO to separate wrist traumatology from that of the hand which was published in 2016 . This highly practical and richly illustrated book thus presents surgical techniques for the lower extremity of the radius and ulna as well as for fractures and dislocations fracture of the wrist bones.

The first part deals with the most common approaches. The second part deals with fractures and fractures dislocations of carp including vascularized grafts for the scaphoid. The third part deals with problems related to the distal ulnar radio articulation. The fourth part deals with simple or complex fractures of the radius. The last part deals with the reconstruction of vicious callus and treatments of osteoarthritis.

The presentation by clinical case allows step by step from the indication to the postoperative care to follow the course of treatment and its results.
It is therefore a book and a very complete e-book that will interest both the novice surgeon to learn the techniques and the confirmed surgeon who seeks a technical point on an operation he does not practice fluently.

\section{Compliance with ethical standards}

Conflict of interest The authors declare that they have no competing interests.

Publisher's Note Springer Nature remains neutral with regard to jurisdictional claims in published maps and institutional affiliations.
Pierre H. Kehr

pierre.kehr@gmail.com

1 Strasbourg, France 